\title{
Corrigendum: Global Patterns in Marine Sediment Carbon Stocks
}

\author{
Trisha B. Atwood ${ }^{1 *}$, Andrew Witt', Juan Mayorga ${ }^{2,3}$, Edd Hammill ${ }^{1}$ and Enric Sala ${ }^{2}$ \\ ' Department of Watershed Sciences and Ecology Center, Utah State University, Logan, UT, United States, ${ }^{2}$ National \\ Geographic Society, Washington, DC, United States, ${ }^{3}$ Bren School of Environmental Science \& Management and Marine \\ Science Institute, University of California, Santa Barbara, Santa Barbara, CA, United States
}

Keywords: blue carbon, soil carbon, carbon storage, climate mitigation, carbon cycle, SOC

\section{A Corrigendum on}

Global Patterns in Marine Sediment Carbon Stocks

by Atwood, T. B., Witt, A., Mayorga, J., Hammill, E., and Sala, E. (2020). Front. Mar. Sci. 7:165. doi: $10.3389 /$ fmars.2020.00165

In the original article, there was a mistake in Table 2 as published. There was an error in how we summed the sediment carbon stocks for the global ocean and each location (i.e., province, jurisdiction, ocean depth, and MPA status). The corrected Table 2 appears below.

Several corrections have been made to the text of the article, to reflect the changes made to the data in Table 2, and the updated sections are as follows:

Abstract: " 3117 (3006-3209) Pg C in the top 1 m" was changed to "2322 (2239-2391) Pg C in the top $1 \mathrm{~m}$." The full corrected text is "Here we quantify global marine sedimentary C stocks at a $1-\mathrm{km}$ resolution, and find that marine sediments store $2322(2239-2391) \mathrm{Pg} \mathrm{C}$ in the top $1 \mathrm{~m}$ (nearly twice that of terrestrial soils). Sediments in abyss/basin zones account for $79 \%$ of the global marine sediment C stock, and 49\% of that stock is within the 200-mile Exclusive Economic Zones of countries."

Results, paragraph 2: "We found that the global ocean stores $3117 \mathrm{Pg}$ of $\mathrm{C}$ in the top $1 \mathrm{~m}$ (Figure 6A), with a 3006 to $3209 \mathrm{Pg} \mathrm{C}$ range across all pixels." was changed to "We found that the global ocean stores $2322 \mathrm{Pg}$ of $\mathrm{C}$ in the top $1 \mathrm{~m}$ (Figure 6A), with a 2239 to $2391 \mathrm{Pg} \mathrm{C}$ range across all pixels."

Results, paragraph 3: "2240-2395 Pg C" was changed to "1777-1898 Pg C", "490-523 Pg C" was changed to "256-274 Pg C," "218-233 Pg" was changed to "164-175 Pg," "30-31.4 Pg" was changed to "23-24 Pg," "28-29.6 Pg" was changed to "19-20 Pg," "1606 (218-233, 95\% CI)" was changed to "1132 (1092-1166, 95\% CI)," "1512 (1480-1580)" was changed to "1190 (1147-1225)," "118 (114-122)" was changed to "94 (92-97)," and "57 (54-58)" was changed to "48 (47-50)."

The full corrected text is "Carbon stocks spatially varied across oceanic depths and across regions. Five-times as much C is stored in deep-sea sediments (water depths $>1000 \mathrm{~m}$ ) compared to sediments underlying shallow seas (Table 2). Within the oceanic provinces, abyssal/basins store the most C (1777-1898 Pg C), followed by the continental shelf (256-274 Pg C), the continental slope (164-175 Pg), hadal zone (23-24 Pg), and other non-shelf coastal habitats (19-20 Pg). The amount of C stored in EEZs and the high seas were similar, with 1132 (1092-1166, 95\% CI) Pg C stored in EEZs and 1190 (1147-1225) Pg C stored in the high seas. As of 2019, 94 (92-97) Pg C in the top $1 \mathrm{~m}$ of sediments is stored in MPA's, of which only $48(47-50)$ Pg C is stored in highly protected MPAs (Figures 6A,C and Table 2)." 
TABLE 2 | Global extent, average (95\% confidence intervals) carbon (C) stocks in the top $1 \mathrm{~m}$, and proportion of the global marine sediment C stock in the top $1 \mathrm{~m}$ for different oceanic provinces, marine jurisdictions [Exclusive Economic Zones (EEZ)], ocean depths, marine protected areas (MPAs), including implemented highly and fully protected areas, and total marine sedimentary C stock for the global ocean.

\begin{tabular}{|c|c|c|c|c|c|}
\hline & Area km² & C stock (Mg km²) & Total sediment C stocks $(\mathrm{Pg})$ & Global proportion & \# of cores \\
\hline \multicolumn{6}{|l|}{ Oceanic Provinces } \\
\hline Continental Shelf & $14,250,873$ & $18,666(17,964-19,227)$ & 266 (256-274) & $11.5 \%$ & 5450 \\
\hline Other Coastal & $4,894,100$ & $3,882(3,882-4,087)$ & $19(19-20)$ & $0.8 \%$ & 856 \\
\hline Continental Slope & $19,693,306$ & 8,632 $(8,328-8,886)$ & $170(164-175)$ & $7.3 \%$ & 2261 \\
\hline Abyss/Basin & $306,595,886$ & $6,014(5,796-6,191)$ & $1844(1777-1898)$ & $79.4 \%$ & 2981 \\
\hline EEZs & $167,345,228$ & $6,764(6,525-6,968)$ & $1132(1092-1166)$ & $48.8 \%$ & 9610 \\
\hline High Seas & $181,526,865$ & $6,556(6,319-6,748)$ & $1190(1147-1225)$ & $51.2 \%$ & 1968 \\
\hline \multicolumn{6}{|l|}{ Ocean depth } \\
\hline Shallow sea $(<1000 \mathrm{~m})$ & $31,687,886$ & $11,361(10,951-11,708)$ & $360(347-371)$ & $15.5 \%$ & 7692 \\
\hline Deep-sea (>1000 m) & $317,184,207$ & $6,186(5,965-6,369)$ & $1962(1892-2020)$ & $84.5 \%$ & 3886 \\
\hline \multicolumn{6}{|l|}{ Total C stocks } \\
\hline Global marine sediments & $348,872,093$ & $6,656(6,418-6,854)$ & $2322(2239-2391)$ & & 11,578 \\
\hline Global terrestrial soil & $125,800,000$ & & 1325 & & \\
\hline
\end{tabular}

The number of cores indicates the sample size for each category. Terrestrial soil stocks and land area estimates are from Köchy et al. (2015).

Discussion, paragraph 1: “ 3117 (3006-3209)” was changed to "2322 (2239-2391)," "most (75\%)" was changed to "most (79\%)," "with 2.3 times" was changed to "with 1.75 times," and "our estimate is $\sim 1.8$ times to 6 times greater" was changed to "our estimate is 1.3 times to 4.7 times greater."

The full corrected text is "We estimate that the ocean is currently storing 2322 (2239-2391) Pg C in the top $1 \mathrm{~m}$ of sediments, with most (79\%) of this C stored in abyssal/basin zones. This estimate makes the ocean the largest pool of sediment/soil C stocks in the world, with 1.75 times greater C stocks than the top $1 \mathrm{~m}$ of terrestrial soils (Köchy et al., 2015). Because our estimate does not include supratidal areas, our C stock estimate is likely conservative as it omits some supratidal marshes and mangroves, which are known to store large amounts of sediment C (Atwood et al., 2017; Macreadie et al., 2017; Osland et al., 2018). Past studies have estimated that marine surface sediments store between $87 \mathrm{Pg} \mathrm{C}$ (top $5 \mathrm{~cm}$; Lee et al., 2019) and $147 \mathrm{Pg} \mathrm{C}$ (top $30 \mathrm{~cm}$; Emerson and Hedges, 1988); if we extrapolate their results to a $1 \mathrm{~m}$

\section{REFERENCES}

Atwood, T. B., Connolly, R. M., Almahasheer, H., Carnell, P. E., Duarte, C. M., Lewis, C. J. E., et al. (2017). Global patterns in mangrove soil carbon stocks and losses. Nat. Clim. Chang. 7, 523-528. doi: 10.1038/NCLIMATE3326

Emerson, S., and Hedges, J. I. (1988). Processes controlling the organic carbon content of open ocean sediments. Palaeogeogr. Palaeoclimatol. Palaeoecol. 3, 621-634. doi: 10.1029/PA003i005p00621 depth (assuming an equal distribution of $\mathrm{C}$ with depth), our estimate is 1.3 times to 4.7 times greater, respectively, than these previous calculations.

Discussion, paragraph 3: “ $80 \%$ " was changed to " $84 \%$." The full corrected text is "However, because of their extensive geographic areal coverage, deep-sea sediments accounted for $84 \%$ of the total marine sediment C stock."

Discussion, paragraph 5: “ $4 \% \quad(\sim 118$ Pg C $)$ " was changed to " $4 \%$ (94 Pg C)" and " 2\% (57 Pg C)" was changed to " $2 \%(48 \mathrm{Pg}$ C)." The full corrected text is "Currently, 4\% (94 Pg C) of marine sediment C stocks occur in MPAs, and only $2 \%$ (48 $\mathrm{Pg} \mathrm{C}$ ) occur in highly protected MPAs where commercial extraction is prohibited, and recreational and subsistence extraction is minimal (i.e., no-take reserves)."

The authors apologize for this error and state that this does not change the article's major scientific conclusions in any way, nor did it affect the validity or fit of Random Forest regression model. The original article has been updated. 
Macreadie, I., Ollivier, Q. R., Kelleway, J. J., Serrano, O., Carnell, P. E., Ewers Lewis, C. J., et al. (2017). Carbon sequestration by Australian tidal marshes. Sci. Rep. 7:44071. doi: 10.1038/srep44071

Osland, M. J., Gabler, C. A., Grace, J. B., Day, R. H., McCoy, M. L., McLeod, J. L., et al. (2018). Climate and plant controls on soil organic matter in coastal wetlands. Glob. Chang. Biol. 24, 5361-5379. doi: 10.1111/gcb.1 4376
Copyright $\odot 2021$ Atwood, Witt, Mayorga, Hammill and Sala. This is an open-access article distributed under the terms of the Creative Commons Attribution License (CC $B Y)$. The use, distribution or reproduction in other forums is permitted, provided the original author(s) and the copyright owner(s) are credited and that the original publication in this journal is cited, in accordance with accepted academic practice. No use, distribution or reproduction is permitted which does not comply with these terms. 